Original article

https://www.journal-imab-bg.org

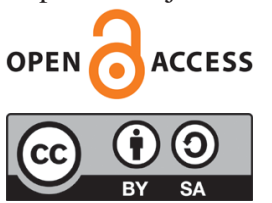

\title{
EFFECTIVENESS OF ERGOTHERAPEUTIC AND OCCUPATIONAL THERAPEUTIC PROGRAM IM- PLEMENTED FOR CHILDREN AND YOUTHS WITH DISABILITIES IN FAMILY-TYPE RESIDEN- TIAL CENTERS
}

\author{
Danelina Vacheva ${ }^{1}$, Iskra Petkova ${ }^{2}$ \\ 1) Department of Physical Medicine, Rehabilitation, Occupational Therapy and \\ Sports, Medical University - Pleven, Bulgaria \\ 2) Department of Social and Pharmaceutical Activities, Medical University - \\ Pleven, Bulgaria.
}

\begin{abstract}
:
The purpose of this study is to report the effectiveness of ergotherapy and occupational therapy activities included in upbringing and education of children and youths with disabilities that use the social service "Family-type accommodation center".

Materials and Methods: The study included 37 users using the relevant social service in the Municipality of Pleven, distributed by age groups and degree of disability. A survey was conducted with 26 employees in these Centers to determine the impact of the program on consumer development. Tests were performed to assess the skills for independent daily life. The obtained results were processed statistically to determine their significance.

Results: The data from the study show a statistically significant positive impact of the selected ergo- and occupational therapy program in children and young people with disabilities raised in Family-type Centers, and is most significant in children of preschool and primary school age. The improvement in young people with severe physical and mental disabilities is expected to be insignificant, but the results of the survey of employees show a positive effect on their psycho-emotional state.

Conclusion: Inclusion of an appropriate ergo- and occupational therapy program in the upbringing and education of children and young people with disabilities, who are in a disadvantaged social position and use social services, has a favorable impact on the formation of their skills for independent living.
\end{abstract}

Keywords: occupational therapy, labor therapy, children with disabilities, activities of daily living (ADL), social service,

\section{INTRODUCTION:}

Medico-social and socio-pedagogical work with children and young people in disadvantaged social situations require professional competencies adequate to the dynamic social changes related to their preparation for independent living [1]. This issue is especially relevant and important for children and young people with disabilities when they are raised outside the family environment and the measure accommodation of resident type as a social service "Family type accommodation Centre" has been applied [2]. To maintain the health of these children, a number of specialists work together to form the so-called "Rehabilitation team" and who together explore and discuss their individual physical and mental condition [3]. The rehabilitation team, depending on age and health, includes different types of specialists: physician - specialist, kinesitherapist, medical physiotherapist, nurse, occupational therapist, ergotherapist, occupational therapist, pedagogue, psychologist, speech therapist, social worker, etc. [4]. For children with disabilities, a specialized activity related to training and facilitation of daily life activities (DLA) [5] is applied, which is the essence of the ergotherapy [6], and the occupational therapy uses a variety of occupational activities for therapeutic purposes [7, 8].

According to the definition of the WHO Constitution, "health" does not mean the absence of disease, but a "complete physical, mental and social well-being" [9]. The physical well-being of the human body is taken care of by medical rehabilitation with its main therapeutic directions of natural and reformed physical factors [10]. Mental wellbeing is considered to be the ability of a person to be independent in his daily life and to achieve professional realization [11]. Social well-being is expressed through normal family and friendly relations, communication and inclusion in the social environment [12]. If due to permanent structural and functional changes in the organs and systems of the human body damages occur to the musculoskeletal system and/or mental problems leading to inability to perform self-care, it is necessary to create compensatory mechanisms and adapt to the most appropriate vocational retraining, psychological and social readaptation of the individual [13]. This is the essence of ergotherapy [14].

The purpose of this study is to report the effectiveness of ergotherapy and occupational therapy activities in- 
cluded in upbringing and education of children and youths with disabilities that use the social service "Family-type accommodation center".

\section{MATERIALS AND METHODS: \\ Scope of the study}

1. The study included persons who currently use the social service "Family-type accommodation center" on the territory of Municipality of Pleven. We examined 37 users, divided by age groups, degree of intellectual disability and motor impairment (preschool age - 4 children; primary school age - 9 children; secondary school age -2 users; young people with intellectual disabilities - 13 and people with physical disabilities and intellectual insufficiency -9). Of all participants in the study, 23 are male, and 14 are female (gender is important for the selection of appropriate work and household activities).

The participants in the study are divided into 3 groups depending on their age and individual physical and intellectual condition:

Group I - children of preschool and school-age - 15; ties -13 ;

Group II - young people with intellectual disabili-

Group III - young people with motor disabilities and intellectual disabilities -9 .

All participants received a personal number (PN from 1 to 37) in alphabetical order of their first names, following the order of the groups.

2. A survey was conducted on a voluntary basis, with 26 employees of the social service department. A standardized questionnaire has been developed, containing the main question "To what extent, in your opinion, participation in an ergo- and occupational therapy program for children and young people using social services (Family-type accommodation center) will have an impact on ...".

\section{Research methods and tools}

$>$ Clinical methods - systematization of the medical documentation of the persons with disabilities;

$>$ Functional studies (age-appropriate for children) that include a "Daily Performance Test" (ADL) in three stages [15]:

1. inability to perform the tested activity;

2. performing the tested activity with the need for assistance;

3. ability to perform the tested activity independently.
$>$ Sociological methods - (questionnaire): conducting a survey among the employees of "Six family-type accommodation Centers" - Pleven. Grades are determined by the 5-point Likert scale: 1 - no; 2 - rather not; 3 - I can not judge; 4 - rather yes; 5 - yes.

$>$ Statistical methods - the obtained results are processed with statistical program SPSS, Wilcoxon rank test, t-test of Student. The significance of the results for conclusions was determined at $\mathrm{p}<0,05$.

\section{RESULTS:}

The developed and approbated occupationally, and ergotherapy program is in accordance with the age and individual characteristics of the users of the social service [16]. In the present study, the results obtained from the functional test for performing DLA with its 4 sections are presented and analyzed:

- ability to use toiletry and maintain personal hygiene;

- ability to put on clothes and shoes;

- ability to prepare and eat meal independently;

- ability to perform household and work activities.

The data obtained at the beginning and at the end of the study period (before and after application of an appropriate ergo- and occupational therapy program) and the difference between the end and the beginning of the study period (improvement) are subjected to statistical processing. The arithmetic mean (X) of the numerical image from the corresponding test scale is used.

The working hypothesis of the study is: The applied ergo- and occupational therapy program have a positive effect on the formation of skills for the self-reliant and independent daily life of the users of the social service.

Figures 1, 2, and 3 present the individual results of the persons per group at the beginning and at the end of the study, which show improved independence of children and youths due to the applied ergotherapy program. This improvement is most significant in children of preschool and school-age. The improvement in young people with severe physical and mental disabilities is expected to be insignificant. For young people with intellectual disabilities, Pergamum's famous claim since ancient times that "Work is the best teacher of nature and is indispensable for human happiness" was confirmed, with a significant improvement in independence and a positive impact on their psycho-emotional state.

Fig. 1. Individual results of the test for ADL before and after the program of Ist group subjects

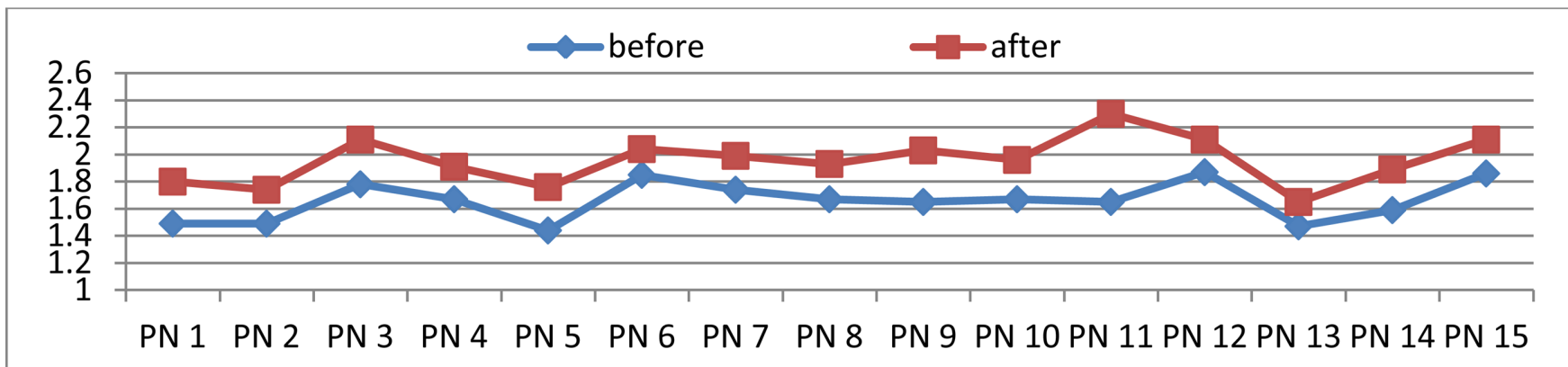


Fig. 2. Individual results of the test for ADL before and after the program of group IInd group subjects

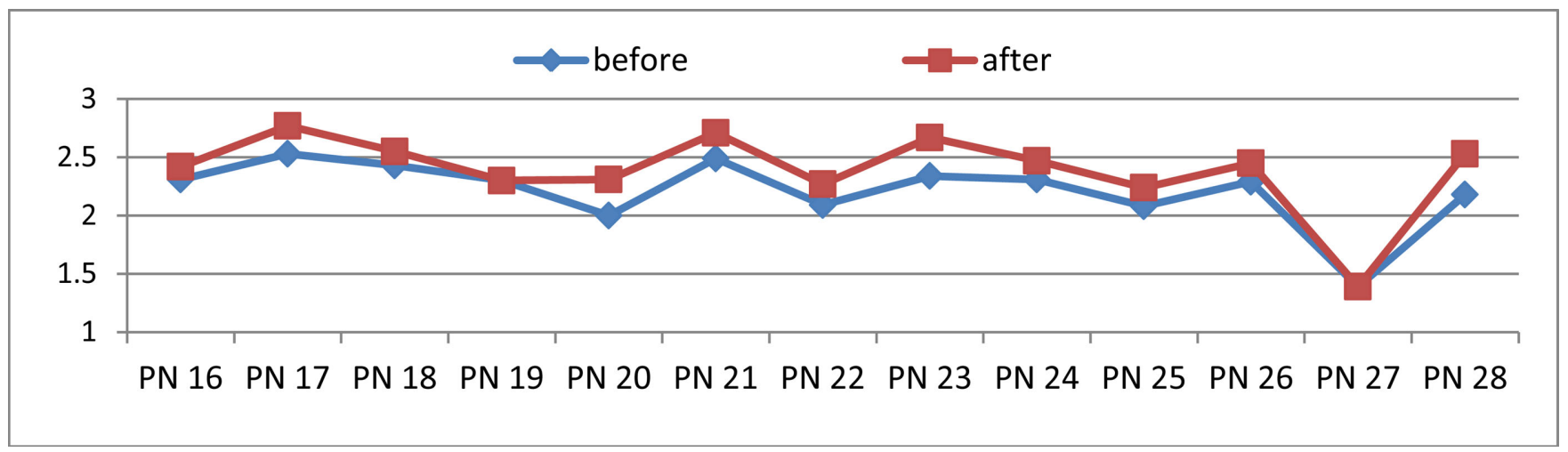

Fig. 3. Individual results of the test for ADL before and after the program of group IIIrd group subjects

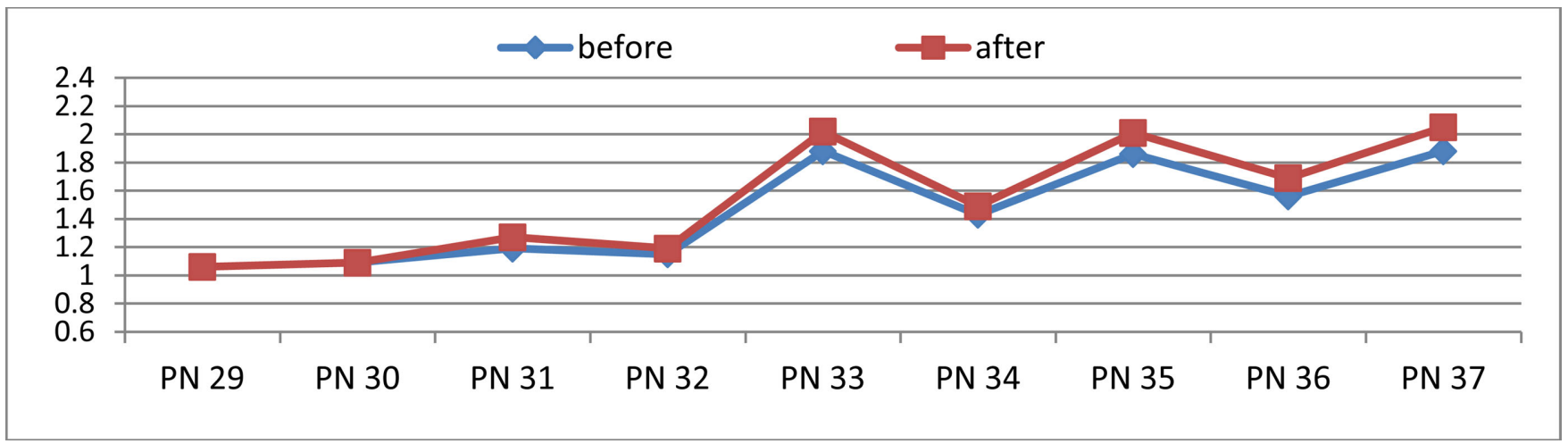

Figure 4 presents the results of the DLA test per group of activities and group of participants. The graph demonstrates an identical ability to perform separate groups of everyday life activities. The initial condition of young people with intellectual disabilities (group II) is significantly better compared to children of preschool and primary school age (group I) and the group of young people with motor and mental disabilities (group III).

Fig. 4. Results of the test for ADL by groups of activities before and after the program by groups of subjects

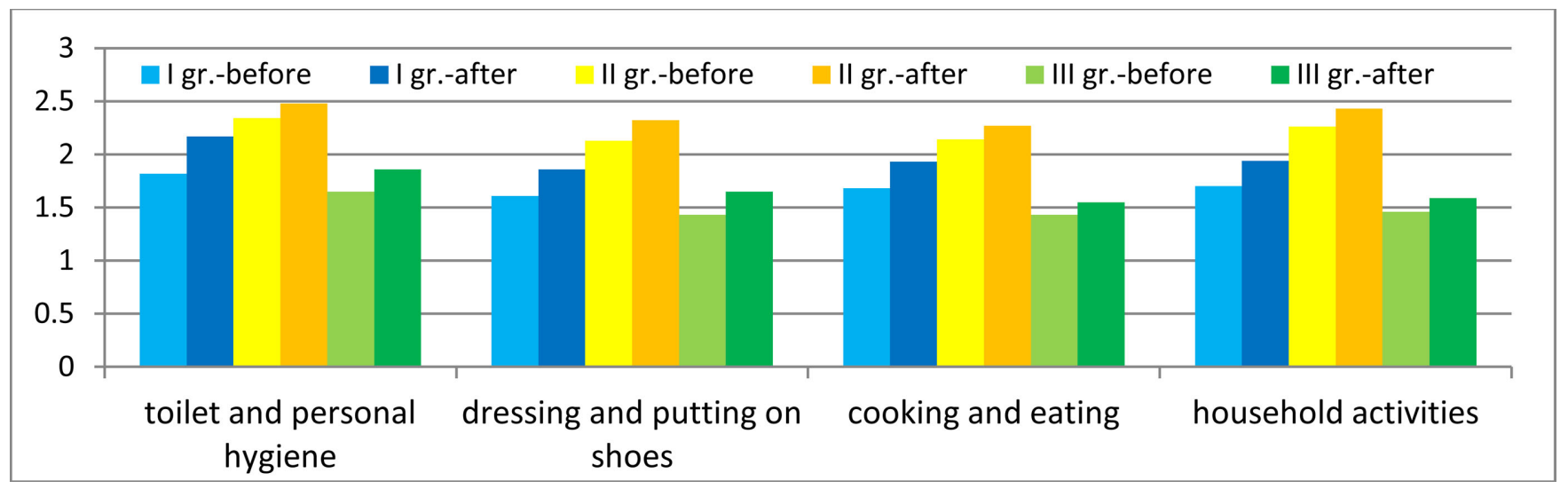

The improvement (the difference between the end and the beginning of the observed period) in the individual groups is presented in fig. 5 . 
Fig. 5. Results of the test for ADL by groups of subjects before and after the program

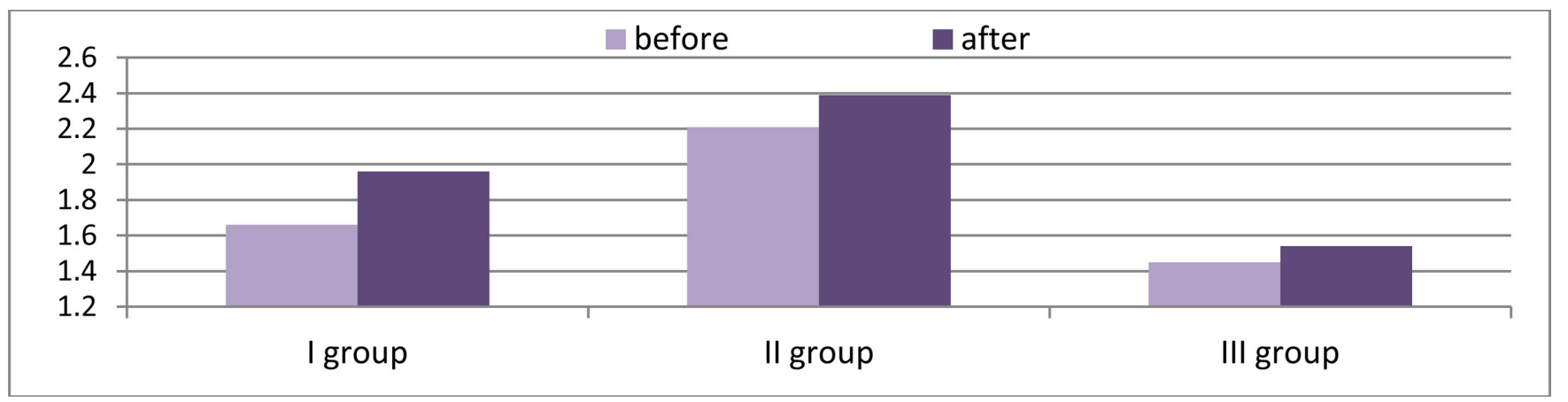

Table 1 presents data from statistical processing of the obtained DLA test results at the beginning, at the end and the difference (improvement) from conducted observation on participants per group. The working hypothesis for the users from the group I was confirmed. For young people with motor and mental disabilities (III group), it is insignificant, and for those with intellectual disabilities (II group), it is of low importance.

Table 1. Results from the statistical processing of the test for DLA before, after and difference from the conducted program

\begin{tabular}{|l|c|c|c|c|c|c|c|c|c|c|c|}
\hline \multirow{2}{*}{ group } & \multirow{2}{*}{$\mathbf{n}$} & \multicolumn{3}{|c|}{ Beginning of the study } & \multicolumn{3}{|c|}{ End of the study } & \multicolumn{3}{|c|}{ Difference } & \multirow{2}{*}{ t-test } \\
\cline { 3 - 11 } & & $\overline{\mathbf{X}}$ & $\mathbf{S}$ & $\mathbf{C I}$ & $\overline{\mathbf{X}}$ & $\mathbf{S}$ & $\mathbf{C I}$ & $\overline{\mathbf{X}}$ & $\mathbf{S}$ & $\mathbf{C I}$ & \\
\hline I group & 15 & 1,66 & 0,14 & $\pm 0,07$ & 1,96 & 0,19 & $\pm 0,10$ & 0,30 & 0,21 & $\pm 0,11$ & 3,05 \\
\hline II group & 13 & 2,21 & 0,29 & $\pm 0,16$ & 2,39 & 0,33 & $\pm 0,18$ & 0,18 & 0,12 & $\pm 0,07$ & 0,16 \\
\hline III group & 9 & 1,45 & 0,35 & $\pm 0,23$ & 1,54 & 0,41 & $\pm 0,27$ & 0,09 & 0,07 & $\pm 0,05$ & 0,64 \\
\hline
\end{tabular}

Table 2 presents responses to the survey among employees who provide care to users of social services. Despite the slight improvement in the independence of young people with disabilities, employees indicate responses on the positive side of the scale, which demonstrates influence on their psycho-emotional behavior and their desire to be actively involved in daily activities.

Table 2. Results of a survey conducted among the employees of the social service "Family-type accommodation center" in \%

\begin{tabular}{|l|c|c|c|c|c|}
\hline $\begin{array}{l}\text { Question } \\
\text { Degree }\end{array}$ & $\mathbf{1}$ & $\mathbf{2}$ & $\mathbf{3}$ & $\mathbf{4}$ & $\mathbf{5}$ \\
\hline 1. Activity in the process of performing ADL & 0 & 15,38 & 7,69 & 42,31 & 34,62 \\
\hline $\begin{array}{l}\text { 2. Independence of the user in the implementation } \\
\text { of ADL }\end{array}$ & 11,54 & 11,54 & 7,69 & 30,77 & 38,46 \\
\hline $\begin{array}{l}\text { 3. Increasing the consumer's interest in occupational } \\
\text { therapy activities }\end{array}$ & 7,69 & 7,69 & 11,54 & 42,31 & 30,77 \\
\hline 4. Development of communication skills & 0 & 0 & 7,69 & 57,69 & 34,62 \\
\hline $\begin{array}{l}\text { 5. Development of skills for working with different } \\
\text { materials and techniques }\end{array}$ & 3,85 & 15,38 & 7,69 & 38,46 & 34,62 \\
\hline
\end{tabular}

\section{DISCUSSION:}

In January 2021, a publication in the American Journal of Ergotherapy [17] addressed the occupational therapy of children and adolescents with disabilities, up to the age of 21. The study uses impacts based on elements of professional activity (baking, confectionery, floriculture, gardening), sports and story games or leisure activities and reports a positive impact on the performance of ADL. The published ergotherapy and occupational therapy program is similar to the program we suggest and includes support for the commitment to various professions, support for cognitive participation, facilitation and support of vocational training and implementation of activities. In conclusion, the authors point out that engaging in professional, house- 
hold and work activities in various areas of everyday life improves the functional suitability of the users. The importance of favorite entertaining activities applied arts, and fun games are pointed out, as well as training of caregivers and employees of social institutions in the implementation of ergotherapy program. Such activities are included in the occupational therapy program developed by the author of the article, tailored to the individual capabilities of children and their interests.

The same journal of the American Occupational Therapy Association in 2020 published an article about the impact of the occupational therapy program on young people with mental illness and intellectual disabilities [18]. The authors point out that they have studied people with intellectual disabilities, but without motor disabilities, who have poor cognitive performance and have difficulties coping with professional activities. After the implementation of ergotherapy program, they report a positive effect in the transition from school to professional realization. The authors have researched extensively other results published on this topic, but as we found in the available literature, this issue is not widely discussed. Need for trained staff in occupational and ergotherapy is indicated, as well as training of employees that provide social services. The results of our study confirm the opinion of the cited authors that occupational therapy is poorly represented in the literature describing the services for young people with intellectual disabilities. Although the articles describe occupational therapy programs, we also believe that these interventions have not been provided by occupational therapists and do not have a solid evidence base.

In 2020, in France, a large team of different specialists conducted a multicenter study on the need for rehabilitation, medical care, educational and social support provided in French schools to children of different ages with different neuropsychological profiles, proving the impor- tance of a multidisciplinary approach for children with genetic diseases [19].

The contributions of this study are expressed through the following:

- the stimulating effect of the earlier inclusion and systematic occupation with ergo- and occupational therapy activities in children with intellectual disabilities was statistically confirmed;

- the implementation of an appropriate program by specialists in this field leads to a significant improvement of the skills for independent living within the development of the personality, which is indisputably proved by the positive results in groups I and II;

- regardless of the young age of users with intellectual disabilities and the short time of the study, the results show a positive effect on their emotional state;

- The results of the survey prove the need for additional training of specialists who work with children and young people with disabilities to apply an occupational and ergotherapy program.

\section{CONCLUSION:}

Inclusion of an appropriate ergo- and occupational therapy program in the upbringing and education of children and young people with disabilities, who are in a disadvantaged social position and use social services, has a favorable impact on the formation of their skills for independent living.

\section{Acknowledgements:}

This study has been funded by the budget of Medical University of Pleven, under Scientific Research Project No.11/2020. Materials, consumables, tools and equipment have been provided for the conduct of ergotherapy and occupational therapy program at the Family-type accommodation centers in Municipality of Pleven, Bulgaria.

\section{REFERENCES:}

1. Petkova I. [Socio-pedagogical work with children deprived of parental care.] Gabrovo: EX-Press; 2012. pp.107-14. [in Bulgarian]

2. [Methodical guide - Center for accommodation of family type children.] [in Bulgarian] Agency for Social Assistance, Sofia. 2008. pp.4-6. [Internet]

3. Ivkov B. [Short terminological dictionary of rehabilitation.] [in Bulgarian] bojidarivkov-Sociology of disability. August 17, 2012. [Internet]

4. Koleva I. [Principles of modern physical and rehabilitation medicine.] 2nd Edit. Sofia: RIK Simel; 2007. pp.15-24. [in Bulgarian]

5. Paskaleva R, Pavlova V, Ivanova $\mathrm{V}$. [Occupational therapy and game therapy in children with cerebral injuries.] Varna Medical Forum. 2015; 4(suppl. 3):108-12 pp. [in Bulgarian]

6. Mincheva P. [Occupational therapy in pediatrics.] Publishing House Ruse University. 2018. pp.5-9. [in Bulgarian]

7. Mizgarov EO. Occupational therapy as a direction of social rehabilitation of children with disabilities. Forms and methods of social work in various spheres of life. Ed. Yu. Yu. Shurygina. Materials of the III International Scientific and Practical Conference, 2014 December 9-10; Ulan: East Siberian State University of Technology and Management; 152-4 pp. [in Russian]
8. Paskaleva R, Uzunova A. Role of art-therapy for psycho-emotional and physical stimulation of the elderly. Research in Kinesiology. 2015; 43(2):239-41.

9. WHO remains firmly committed to the principles set out in the preamble to the Constitution. [Internet]

10. Ryazkova M. [Physiotherapy and rehabilitation.] Sofia: ARSO; 2002. pp.253-6. [in Bulgarian]

11. Topuzov I. [Occupational therapy.] First part. Sofia: RIK Simel; 2006. pp.310-11. [in Bulgarian]

12. Rangelova Ts, Peneva Z, Peteva S, Manolova P. Development of skills for independent living. Handbook for working with children. Foundation "Partners-Bulgaria". 
2007. pp.5-6. [in Bulgarian]

13. Punwar AJ, Peloquin SM. Occupational Therapy Principles and Practice. 3rd Edition. Lippicott Williams \& Wilkins. 2000. [Internet]

14. Vacheva D. [Guide for teaching and clinical practice in occupational therapy.] Publishing Center of Medical University - Pleven. 2017. 12-16 pp. [in Bulgarian]

15. Rusk HA. Rehabilitation medicine;: A textbook on physical medicine and rehabilitation. 2nd edition. Mosby. January 1, 1964. 668p. [Internet]
16. Vacheva D, Petkova I. [Program for medical and social rehabilitation of disadvantaged children.] Management and Education. 2020; XVI(6):138-47 pp. [in Bulgarian]

17. Laverdure P, Beisbier S. Occupation- and Activity-Based Interventions to Improve Performance of Activities of Daily Living, Play, and Leisure for Children and Youth Ages 5 to 21: A Systematic Review. Am J Occup Ther. 2021 Jan-Feb;75(1): 7501205050. [PubMed] [Crossref]

18. Rosner T, Grasso A, Scott-Cole L, Villalobos A, Mulcahey MJ.
Scoping Review of School-to-Work Transition for Youth With Intellectual Disabilities: A Practice Gap. Am J Occup Ther. 2020 Mar-Apr;74(2): 7402205020. [PubMed] [Crossref]

19. Roux-Levy PH, Bournez M, Masurel A, Jean N, Chancenotte S, Bordes M, et al. Associations between cognitive performance and the rehabilitation, medical care and social support provided to French children with Prader-Willi syndrome. Eur J Med Genet. 2020 Dec;63(12): 104064. [PubMed] [Crossref]

Please cite this article as: Vacheva D, Petkova I. Effectiveness of ergotherapeutic and occupational therapeutic program implemented for children and youths with disabilities in family-type residential centers. J of IMAB. 2021 JanMar;27(1):3624-3629. DOI: https://doi.org/10.5272/jimab.2021271.3624

Received: 02/07/2020; Published online: 22/03/2021

Address for correspondence:

Assoc. Prof. Danelina Emilova Vacheva,

Department of Physical Medicine, Rehabilitation, Occupational Therapy and Sports, Medical University - Pleven,

1, Kliment Ohridski Str., Pleven, Bulgaria.

E-mail: danelina@abv.bg 